\title{
Integrating child and adolescent psychiatry and the field of early childhood development
}

\author{
Guilherme V. Polanczyk ${ }^{1}$ - Daniel Fatori ${ }^{1}$ - Alicia Matijasevich ${ }^{2}$
}

Published online: 28 February 2018

c) Springer-Verlag GmbH Germany, part of Springer Nature 2018

Accelerated processes of brain development and maturation occur during the first years of life and lead to the initial structuring of cognitive and emotional functions. Due to the intense brain plasticity at this time of life, environmental stimuli can direct substantial changes in functioning and also in the structure of the developing brain, in a positive or negative way [1]. In fact, clinical and epidemiological evidence indicates that the origins of educational, social and economic inequalities and chronic diseases, including mental disorders, go back to the first years of life [2]. Despite the relevance of the first years of life for the success of families, communities and nations is very well established, it is estimated that in 2017, there were approximately 150 million stunted children under 5 globally [3]. Children are also disproportionately represented among the extreme poor, representing $46 \%$ of the population living on less than US $\$ 1.90$ per day around the world [4]. Poverty and malnutrition, as well as exposure to family and community stress and violence, negligence, abuse and maltreatment, restricted access to learning experiences and to health care, are important barriers to full development and are associated to various life-long negative health, educational and social outcomes [5] generating an unfavorable economic impact on the development of nations [6].

Increasing evidence suggests that investments on early childhood development can protect and promote brain development, generating health and avoiding negative outcomes, thus leveraging the development of nations [6]. As a result, early childhood development is increasingly present on the agenda

Guilherme V. Polanczyk

gvp@usp.br

1 Department and Institute of Psychiatry, Hospital das Clinicas HCFMUSP, Faculdade de Medicina, Universidade de Sao Paulo, Rua Dr. Ovídio Pires de Campos 785, São Paulo, SP 05403-010, Brazil

2 Department of Preventive Medicine, Faculdade de Medicina, Universidade de Sao Paulo, São Paulo, SP, Brazil of governments worldwide. Central to early childhood development are sensitive and responsive relationships with parents and caregivers that guarantee health and nutrition, protect from stressors, give opportunities for learning, and allow children to develop healthy emotional and cognitive abilities [7].

In the last decades, a great investment has been directed to the formulation and evaluation of early childhood development programs. Interventions include integrated models that combine elements directed to physical health, cognitive, emotional and social development, with contributions from the health, educational, and social sectors.

The fields of child and adolescent psychiatry and early childhood development have enormous potential of mutual collaboration. Mental disorders are understood to be the result of complex and dynamic interactions between genetic, biological and environmental forces specially occurring during intrauterine period and the first years of life that lead to distortions of normal neurodevelopmental processes [8]. Depending on the moment of development when they occur, the nature and the intensity of the disruptive forces, the disorder can manifest immediately or only years after the initial causal processes arises $[9,10]$. Early stressors affect the emotional structure, and also the architecture of specific brain regions and neural circuitry, increasing the risk of deviant behaviors and mental disorders [11]. Mental disorders underlie several of the outcomes targeted by early childhood development programs (such as aggressiveness, self-control, and cognitive development), are intrinsically related to other chronic disorders (such as obesity and hypertension) [12], and lead to a wide range of negative outcomes throughout life [13, 14]. In addition, parental mental disorders, such as maternal depression, substance use, and paternal criminality, are frequent barriers to the success of early childhood development programs and frequently need focused intervention [15]. Our field has been developing extensive knowledge on all conditions involving cognitive, emotional, and behavioral disorders, from infancy to late adolescence, from etiology to treatment, across the world, as the studies published in this issue of the European Child and 
Adolescent Psychiatry can attest, and can definitely contribute to the development and improvement of early childhood development interventions and their assessment.

On the other hand, promotion and prevention are in the hearts of early childhood development programs, which can contribute to the developmental of this area in our field. Promotion and prevention are being increasingly recognized as a key approach to mental disorders and researchers in our field have already successfully developed and tested interventions targeting depression, anxiety, suicide, schizophrenia, and conduct disorder. Nevertheless, clinical and research accomplishments are necessary before programs become a reality at a population level. Etiological mechanisms of disorders must be elucidated in a way that the frequency of their components can be reduced or their effects are buffered. Disorders must be well characterized, as well as methods to screen and identify individuals who are affected and are at risk to develop the disorder. Finally, costs and risks related to the screening and intervention processes must be clearly defined and benefits must overcome them.

In fact, programs that target specific aspects of development as outcomes are hardly absorbed as public policies. On the other hand, universal and selective prevention programs target multiple outcomes, which increase their cost-benefit and consequently their likelihood to be implemented and scaled-up, articulated with indicated interventions. In this direction, some of the most studied interventions focus on programs for the development of parental competences [16] and on the stimulation of infants during the first 3 years of life [17]. Most of the studies so far have not directly assessed childhood mental disorders, and whether they have an effect on preventing new cases of diagnosable mental disorders is still largely unknown. It is also largely unknown what relevant neurobiological systems are modified by these complex intervention programs, and how biological modifications translate to specific children's behavioral, emotional, and cognitive outcomes. This knowledge has potentially important implications to inform future targeted interventions.

With the increasing public recognition of early childhood development as key to the future of nations and the understanding that preventing mental disorders will be important for the success of these initiatives, the opportunities and responsibilities of our field are significant. Integration between the fields and different societal sectors are necessary to translate evidence-based interventions into scalable public programs that are effective in promoting healthy early childhood development. The gains will be inestimable.

\section{Compliance with ethical standards}

Conflict of interest Guilherme V. Polanczyk has served as a consultant to Shire, Teva, and Medice. He has received royalties from Editora Manole. Other authors report no conflicts of interest.

\section{References}

1. Bateson P et al (2004) Developmental plasticity and human health. Nature 430:419-421

2. Gluckman PD, Hanson MA, Cooper C, Thornburg KL (2008) Effect of in utero and early-life conditions on adult health and disease. N Engl J Med 359:61-73

3. UNICEF (2016) The state of the world's children 2016: a fair chance for every child. https://www.unicef.org/publications/ index_91711.html. ISBN: 978-92-806-4838-6

4. UNICEF/WHO/World Bank Group Joint malnutrition estimates (2017) Levels and trends in child malnutrition. https://data. unicef.org/resources/joint-child-malnutrition-estimates-2017edition/

5. Walker SP et al (2007) Child development: risk factors for adverse outcomes in developing countries. Lancet 369:145-157

6. Beddington $\mathrm{J}$ et al (2008) The mental wealth of nations. Nature 455:1057-1060

7. Britto PR, Lye SJ, Proulx K, Yousafzai AK, Matthews SG, Vaivada $T$ et al (2017) Nurturing care: promoting early childhood development. Lancet 389(10064):91-102. https://doi. org/10.1016/S0140-6736(16)31390-3

8. Insel TR (2014) Mental disorders in childhood: shifting the focus from behavioral symptoms to neurodevelopmental trajectories. JAMA 311:1727-1728

9. Su X, Liang H, Yuan W, Olsen J, Cnattingius S, Li J (2016) Prenatal and early life stress and risk of eating disorders in adolescent girls and young women. Eur Child Adolesc Psychiatry 25(11):1245-1253. https://doi.org/10.1007/s00787-016-0848-z

10. Sturrock S, Hodes M (2016) Child labour in low- and middleincome countries and its consequences for mental health: a systematic literature review of epidemiologic studies. Eur Child Adolesc Psychiatry 25(12):1273-1286. https://doi.org/10.1007/ s00787-016-0864-z

11. Bick J, Nelson CA (2016) Early adverse experiences and the developing brain. Neuropsychopharmacology 41:177-196

12. Tevie J, Shaya FT (2015) Association between mental health and comorbid obesity and hypertension among children and adolescents in the US. Eur Child Adolesc Psychiatry 24(5):497502. https://doi.org/10.1007/s00787-014-0598-8

13. Thielen FW, Ten Have M, de Graaf R, Cuijpers P, Beekman A, Evers S, Smit F (2016) Long-term economic consequences of child maltreatment: a population-based study. Eur Child Adolesc Psychiatry 25(12):1297-1305. https://doi.org/10.1007/ s00787-016-0850-5

14. Zbar A, Surkan PJ, Fombonne E, Melchior M (2016) Early emotional and behavioral difficulties and adult educational attainment: an 18-year follow-up of the TEMPO study. Eur Child Adolesc Psychiatry 25(10):1141-1143. https://doi.org/10.1007/ s00787-016-0858-x

15. Cuijpers P, Weitz E, Karyotaki E, Garber J, Andersson G (2015) The effects of psychological treatment of maternal depression on children and parental functioning: a meta-analysis. Eur Child Adolesc Psychiatry 24(2):237-245. https://doi.org/10.1007/ s00787-014-0660-6

16. Olds D et al (1998) Long-term effects of nurse home visitation on children's criminal and antisocial behavior: 15-year followup of a randomized controlled trial. JAMA 280:1238-1244

17. Walker SP, Chang SM, Powell CA, Grantham-McGregor SM (2005) Effects of early childhood psychosocial stimulation and nutritional supplementation on cognition and education in growthstunted Jamaican children: prospective cohort study. Lancet 366(9499):1804-1807 